\title{
Teleconnections between Snow Cover Change over Siberia and Crop Growth in Northeast China
}

\author{
Cong Guan ${ }^{1,2,3}$, Lingxue Yu ${ }^{2, * \mathbb{D}}$, Fengqin Yan ${ }^{4}$ and Shuwen Zhang ${ }^{2}$ \\ 1 College of Earth Science, Jilin University, Changchun 130061, China; guancong13@mails.jlu.edu.cn \\ 2 Northeast Institute of Geography and Agroecology, Chinese Academy of Sciences, \\ Changchun 130102, China; zhangshuwen@iga.ac.cn \\ 3 Changchun Institute of Technology, Changchun 130012, China \\ 4 State Key Laboratory of Resources and Environmental Information System, Institute of Geographical \\ Sciences and Natural Resources Research, Chinese Academy of Sciences, Beijing 100101, China; \\ yanfq@1reis.ac.cn \\ * Correspondence: yulingxue@iga.ac.cn; Tel.: +86-1524-312-1961
}

Received: 13 August 2020; Accepted: 14 September 2020; Published: 16 September 2020

\begin{abstract}
Snow cover is a sensitive indicator of climate change, and the variations in snow cover can influence the global climate system and terrestrial water cycling. However, the teleconnections between snow cover changes of the northern hemisphere and the crop growth of Northeast China (NEC) are less documented. In this study, we estimated the correlations between spring snow cover area over Siberia (SSCA) and the regional climate, as well as the crop growth in NEC based on both satellite measurement and observational climate records from 1982 to 2015. The local temperature, including minimum temperature (Tmin) in May-June, maximum temperature (Tmax), and Tmin in July-August, showed significant negative correlations with SSCA. SSCA is found to be negatively correlated to rainfall during the beginning of the growing season, while positively correlated to rainfall during the peak growing season for the agricultural ecosystem of NEC. The remote responses of the normalized difference vegetation index (NDVI) to SSCA varied across different climate zones and different growing periods. The NDVI variations over cold and dry cultivated regions exhibit negative correlations with SSCA in May-June, which is opposite for the wetter areas. The negative correlation between NDVI over the agricultural ecosystem and SSCA during the peak growing season was also detected, implying the variations in SSCA might be an essential driving factor in affecting the crop growth through modifying the regional climate of NEC. In the future, more in situ observations and model simulations should be conducted to verify our results described here, which would have significant implications for maintaining regional food security and sustainable development in Northeast China under the changing climate background.
\end{abstract}

Keywords: snow cover changes; regional climate; vegetation growth; Northeast China; Siberia

\section{Introduction}

Snow on land is a crucial component of the global cryosphere and extremely sensitive to changes in climate [1-3]. Numerous studies have documented a retreat of snow cover over the northern hemisphere (NH) due to global warming in the past several decades [4-6]. From 1922 to 2010, the NH spring snow cover extent has undergone significant reduction and that the rate of decrease has accelerated since the 1970s, which has reached to 0.8 million $\mathrm{km}^{2}$ per decade [7]. Changes in snow cover can, in turn, influence the climate systems through the widely documented snow/albedo feedback $[8,9]$. With higher albedo, snow cover can reflect more solar radiation from the land surface and can significantly influence the Earth's radiation balance [10]. As a result, the retreat of snow cover extent can amplify climate warming through the positive snow/albedo feedback [11]. 
Snow cover changes can not only influence the local climate but also can affect global atmospheric circulation and have a subsequent impact on global climate variations [12]. A study based on the general circulation model reported that the large-scale changes in snow cover over Eurasia have a large, strong teleconnection to the atmospheric field over North America [12]. Bamzai et al. (1999) revealed a significant inverse correlation between winter snow cover over western Eurasia and subsequent summer Indian monsoon rainfall [13]. Wu et al. (2009) suggested the decreased spring Snow Water Equivalent (SWE) in Eurasia may be one of the reasons for severe droughts in North and Northeast China and much more significant rainfall events in South and Southeast China [14]. Zhang et al. (2012) found significant negative correlations between spring snow cover changes over Eurasia and summer air temperature of Northeast China [15]. All of these studies implied the teleconnection between snow cover changes and the global climate.

From another perspective, snow cover changes also have implications on the vegetation growth due to regulating regional energy balance and the water cycle [16-18]. For example, Grippa et al. (2005) indicated that later snowmelt dates and thicker winter snowpacks are significantly correlated to higher normalized difference vegetation index (NDVI) values over Siberia, especially for the high latitude vegetation of boreal regions [16]. Peng et al. (2010) revealed that the winter snow depth is significantly and positively correlated with NDVI in the period May-June for the desert and grassland ecosystems in China [17]. Wang et al. (2013) reported that the declining snow cover could significantly advance the vegetation green-up time in the Tibetan Plateau [18]. However, these studies mainly focused on the impacts of snow cover changes on vegetation at the same location. However, our knowledge about the teleconnection between the snow cover anomalies over $\mathrm{NH}$, such as Siberia and crop growth of other areas are limited, particularly for Northeast China, the central grain-producing region in China.

Therefore, the primary objective of this study is to quantify the relationship between SSCA and regional climate, as well as crop growth in Northeast China from 1982 to 2015 . The study is based on long-term time-series remote sensing data and climate observation records. The regional climate factors and the degree of vegetation growth are defined as corresponding mean values during the beginning growing season (May and June) and peak growing season (July and August), respectively. First, we assess the correlation between SSCA and regional minimum temperature (Tmin), maximum temperature (Tmax), precipitation, and vegetation growth, here described by satellite-derived vegetation greenness index observations (NDVI) [17] for different growing periods. Then, we quantify the sensitivities of agricultural climate factors and crop growth conditions of Northeast China to SSCA. Finally, we discuss the potential impacts of future changes in climate on regional agriculture in Northeast China and give some suggestions for maintaining regional food security and sustainable development.

\section{Materials and Methods}

\subsection{Study Area}

Northeast China (Figure 1) extends from $115^{\circ} 05^{\prime}$ to $135^{\circ} 02^{\prime} \mathrm{E}$ in longitude and from $38^{\circ} 40^{\prime}$ to $53^{\circ} 34^{\prime} \mathrm{N}$ in latitude [19]. The climate in the region belongs to a temperate continental climate, with cold and long winters, as well as short and mild summers [20]. The precipitation is mainly concentrated in summer, which accounts for about $50-70 \%$ of the annual total rainfall. There are significant spatial differences in precipitation. As a result, the region's climate can be separated into humid, semihumid, and semiarid, the details of which have been described in Yu et al. (2015) [21]. 


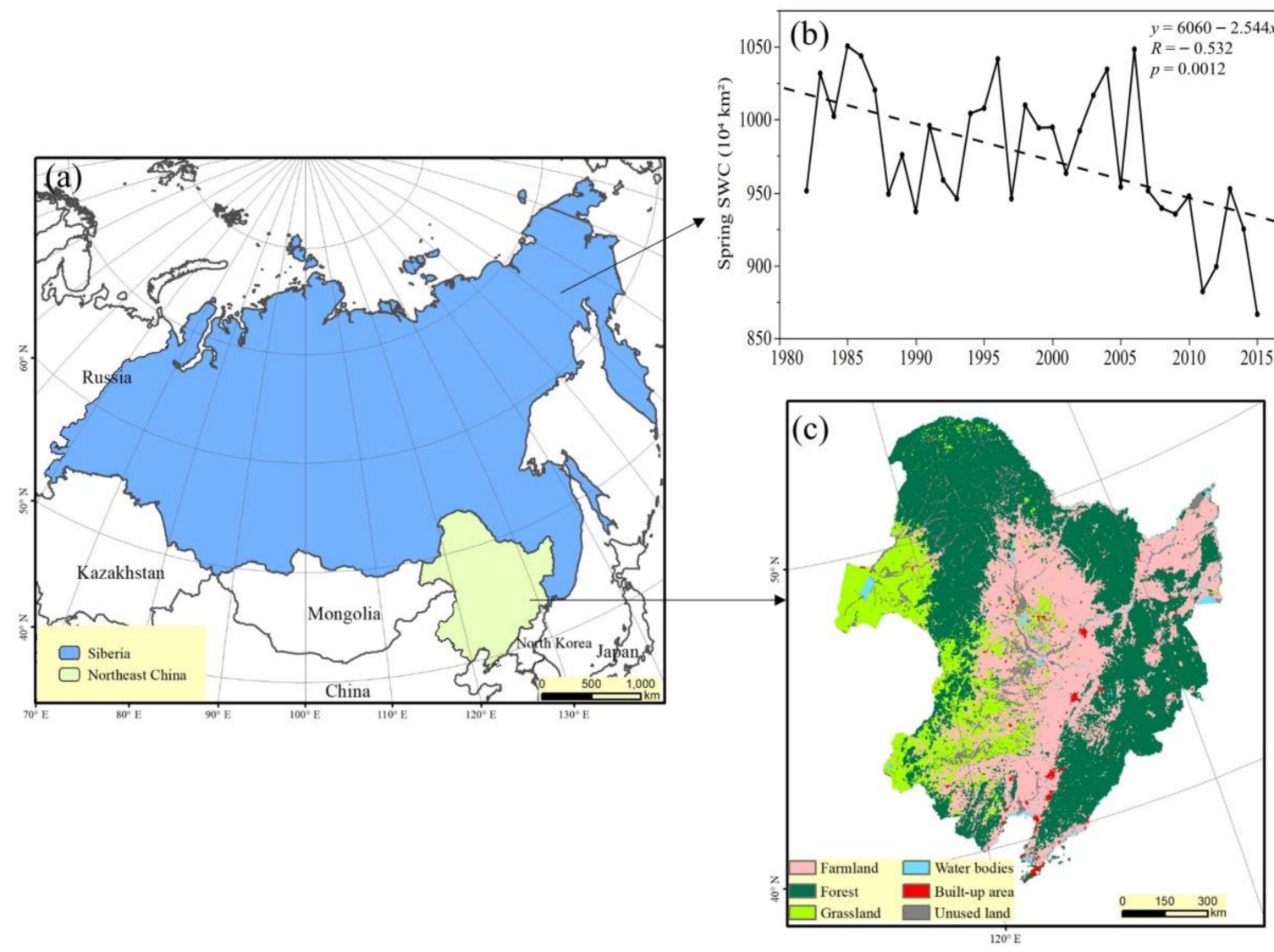

Figure 1. (a) The geographic location of Siberia and Northeast China; (b) the changing trend of spring snow cover area over Siberia from 1982 to 2015; and (c) a land use map of Northeast China.

Forest, farmland, and grassland are the dominant land use types in Northeast China (Figure 1c). With a higher diurnal temperature range, NEC is the optimal grain-producing areas of China. In 2018, grain production of NEC accounted for $20.26 \%$ of China's total production; the region plays a critical role in protecting the food security of China [22]. Some previous studies revealed the impact of snow cover variations in Eurasia on the regional climate anomalies of NEC [14,15,23]. However, the climate responses of NEC to the snow cover variations over western and eastern Eurasia are not consistent [14]. Taking account of the adjacent geographical locations between eastern Eurasia and NEC, in this paper we focused on the regional climate and NDVI responses to snow cover changes over eastern Eurasia (here referring to Siberia). From 1982 to 2015, the snow cover area decreased at a rate of $25.44 \times 10^{4} \mathrm{~km}^{2}$ per decade over Siberia $(R=-0.532, p=0.0012)$. Revealing the relationship between these SSCA anomalies and regional crop growth variations of NEC is our primary objective.

\subsection{Datasets}

The weekly snow cover data over Siberia during the period 1982-2015 was extracted from the Northern Hemisphere EASE-Grid 2.0 Weekly Snow Cover and Sea Ice Extent Version 4 product, which was provided by the National Snow and Ice Data Center of United States (https://nsidc.org/). The snow cover extent of this dataset is based on the NOAA/NCDC Climate Data Record (CDR) of NH Snow Cover Extent (SCE) by Robinson (2012) [24], which was derived from the manual interpretation of AVHRR, GOES, and other visible-band satellite data [25]. The spatial resolution of this dataset is $25 \mathrm{~km}$, which ranges from 3 October 1966 to 31 December 2018. The weekly snow cover data were firstly resampled to $8 \times 8 \mathrm{~km}$ and then calculated through spatial zone statistical analysis based on ArcGIS to obtain the snow cover area over Siberia. In this study, the SSCA for the current year was defined as the spring-averaged snow cover area recorded between 1 March and 31 May. 
Normalized difference vegetation index (NDVI) reflects the vegetation growth and is widely used to monitor the vegetation status at large scales. In this study, we used the NDVI third-generation (3g) data from the Global Inventory Monitoring and Modelling Studies (GIMMS) to analyze the vegetation variations in Northeast China from 1982 to 2015. The GIMMS NDVI-3g data spans from July 1981 to 2015 with an $8 \times 8 \mathrm{~km}$ spatial resolution and 15-day temporal resolution [26], which has been widely used for detecting long-term changes in vegetation at regional or global scales [27,28]. As vegetation generally starts to green-up in early May and reaches its peaks in August over our study area $[19,27]$, the average NDVI from May to June $\left(\mathrm{NDVI}_{\mathrm{MJ}}\right)$ and July to August $\left(\mathrm{NDVI}_{\mathrm{JA}}\right)$ were selected to be the indicators of vegetation growth during the beginning growing season and peak growing season, respectively.

The monthly mean (Tmean), minimum (Tmin), and maximum (Tmax) temperature, and precipitation data over Northeast China, with a spatial resolution of $0.5^{\circ} \times 0.5^{\circ}$ from 1982 to 2015 were obtained from the China Meteorological Administration (CMA), which were generated from approximately 2400 meteorological stations throughout China [29]. The monthly temperature and precipitation were resampled to $0.125^{\circ} \times 0.125^{\circ}$ to match the resolution of NDVI. The multiyear (1982-2015) annual mean temperature and precipitation were used to determine the climate interval over our study area.

As our focus of this study was to detect the influence of snow cover changes in Siberia on agriculture, we also made use of land use and land cover maps for the 1980s and 2015 to extract the unchanged farmland within the study area during our study period. The data were obtained from the National Earth System Science Data Sharing Platform of China and had a spatial resolution of $100 \times 100 \mathrm{~m}$. The datasets were first resampled to $8 \times 8 \mathrm{~km}$ and the unchanged farmland during the 1980 s and 2015 was obtained from the spatial overlay analysis.

\subsection{Analyses}

We used Pearson correlation analysis to evaluate the relationship between SSCA and regional climate/vegetation growth of Northeast China. Pearson's correlation coefficient $(r)$ is a measure of the linear association of two variables and has been widely applied to measure the association between two continuously varying variables [30]. The Pearson correlation requires that the independent and dependent variables show a broadly linear relationship with no outliers or clustering. Because the responses of regional climate and vegetation growth of Northeast China to snow cover changes in Siberia differ for different growing season periods, we analyzed the correlation between variables during the beginning of the growing season and again during the peak growing season for each pixel. Tmax, Tmin, and precipitation were selected as indicators reflecting the regional climate, and NDVI was chosen as the indicator for vegetation growth. We also averaged temperature and precipitation for the unchanged farmland to detect the response of the agricultural environment in Northeast China to the SSCA. The student- $t$ test was conducted to verify the significance of the estimated correlation. When the $p$-value was lower than 0.05 , the correlation was regarded as significant.

For the sensitivity of temperature (Tmax/Tmin) over Northeast China to SSCA, we regressed Tmax/Tmin as a dependent variable with the averaged SSCA as the independent variable:

$$
T=\mathrm{a} \times S S C A+\mathrm{b}
$$

where $\mathrm{a}$ is the regression coefficient and $\mathrm{b}$ is the residual. We defined the regression coefficient of SSCA as the sensitivity of Tmax/Tmin to SSCA. The sensitivity of precipitation and NDVI to SSCA at each pixel is calculated in the same method with temperature. Both the response of NDVI and the sensitivity of NDVI to SSCA in different climate backgrounds, were calculated through statistical analysis during each climate interval. The student- $t$ test was used to calculate the $p$-value and test the significance of the sensitivity. 
Several environmental variables, including temperature, precipitation, and solar radiation, were tested as predictors of NDVI. To discuss the mechanisms of SSCA change in influencing NDVI variations, we used partial correlation analysis to evaluate the relationship between NDVI and local Tmax, Tmin, precipitation, and solar radiation by excluding the confounding effects from other variables [28]. The Tmax variation signal in NDVI was calculated as the partial correlation coefficient between NDVI and Tmax after statistically controlling for interannual variation in Tmin, precipitation, and solar radiation over a 34-year moving window. The Tmin, precipitation, solar radiation variation signal in NDVI were calculated the same way as Tmax. All the dependent and independent variables were detrended before the calculation.

\section{Results}

\subsection{Responses of the Regional Climate of Northeast China to Snow Cover Changes over Siberia}

We first examined the linkage between local climate responses, including Tmax, Tmin, and precipitation of Northeast China to SSCA (Figure 2, Table 1). During the beginning of the growing season, Tmax is positively correlated to SSCA in the central NEC, although it is not significant at $p<0.05$ (Figure 2a). Tmin is negatively correlated to SSCA in most of NEC, which is significant in the northern regions of NEC (Figure 2b). The inconsistent responses of Tmax and Tmin of NEC to SSCA indicate that the SSCA changes may have more potential to influence Tmin other than Tmax. In the Northeast Plain, the main grain production areas over NEC, precipitation anomalies of May and June exhibit negative correlations with variations in SSCA, which is significant at $p<0.05$ (Figure 2c). The responses of the peak growing season temperature and precipitation of NEC to SSCA are quite different from that during the beginning of the growing season. Both the Tmax and Tmin in July and August over NEC showed a negative correlation with SSCA, indicating the increase of snow cover extent over Siberia corresponds to lower daytime and nighttime temperature at the same time. It should be noted that the Tmax of July and August in almost the whole NEC are significantly negatively correlated with SSCA, while for the Tmin only regions in the north part of NEC, mainly located north of $45^{\circ} \mathrm{N}$, are significant $(p<0.05)$ negatively correlated with SSCA. In contrast to the beginning of the growing season, the peak growing season precipitation of NEC except for the North Greater Khingan Range is positively correlated to SSCA, meaning that the greater snow cover extent over Siberia is linked to more rainfall in NEC during July and August.

Table 1. The mean correlation coefficients $\mathrm{R}$ and $p$-value between SSCA and climate factors, including Tmax, Tmin, and precipitation in different regions ${ }^{* *}$ indicates statistically significant at the $95 \%$ confidence level).

\begin{tabular}{ccccccc}
\hline & Tmax_MJ & Tmin_MJ & Prec_MJ $_{-M}$ & Tmax_JA & Tmin $\_$JA & Prec $\_$JA \\
\hline R for regions higher than $45^{\circ} \mathrm{N}$ & -0.01 & -0.38 & -0.23 & -0.36 & -0.45 & 0.06 \\
$p$ value for regions higher than $45^{\circ} \mathrm{N}$ & 0.61 & $0.05^{* *}$ & 0.26 & $0.05^{* *}$ & $0.02^{* *}$ & 0.37 \\
R for regions lower than $45^{\circ} \mathrm{N}$ & 0.04 & -0.17 & -0.08 & -0.4 & -0.2 & 0.26 \\
$p$ value for regions lower than $45^{\circ} \mathrm{N}$ & 0.73 & 0.36 & 0.51 & $0.03^{* *}$ & 0.33 & 0.17 \\
\hline
\end{tabular}

Figure 2 illustrates the temperature and precipitation responses of NEC to SSCA, which also show notable spatial heterogeneity over NEC. As our focus is to unravel the relationship between SSCA and agriculture climate and crop growth of Northeast China, we analyzed the correlation between temperature/precipitation for the agricultural ecosystem of NEC and SSCA (Figure 3). For the agricultural ecosystem of NEC, the R between May- and June-averaged Tmax and SSCA is 0.071 $(p=0.703)$, indicating no significant correlation between SSCA and Tmax. Tmin is negatively correlated with SSCA ( $\mathrm{R}=-0.313, p=0.072)$. The increase of SSCA corresponds to less precipitation over the agricultural ecosystem in May and June, with a negative correlation coefficient of -0.315 ( $p=0.071$ ). 

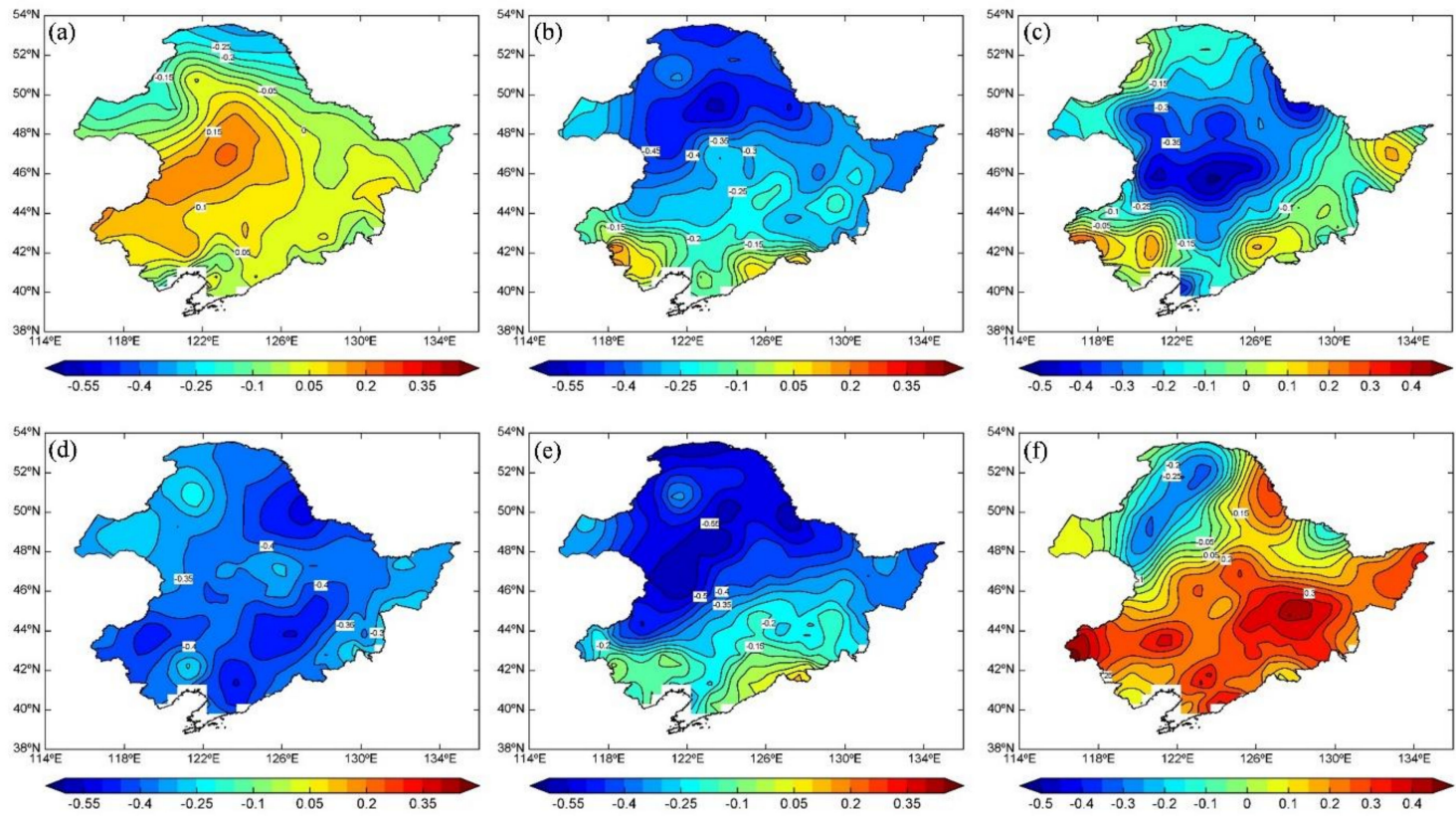

Figure 2. The spatial distribution of correlation between SSCA and Tmax (a), Tmin (b), and precipitation (c) in Northeast China for the beginning growing season (May and June); the spatial distribution of correlation between SSCA and Tmax (d), Tmin (e), and precipitation (f) in Northeast China for the peak growing season (July and August).
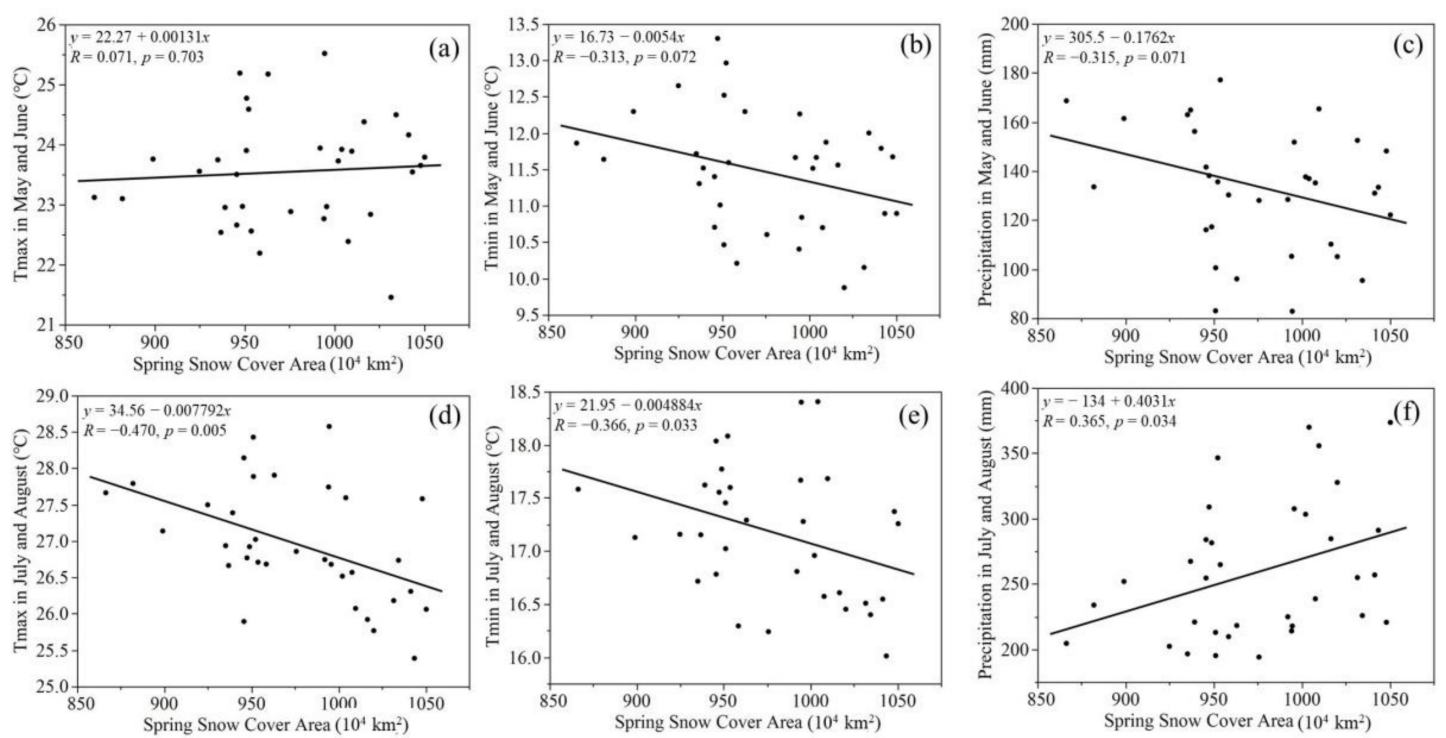

Figure 3. The response of beginning growing season (May and June) Tmax (a), Tmin (b), and precipitation (c) for the agricultural ecosystem of Northeast China to changes in SSCA; the response of peak growing season (July and August) Tmax (d), Tmin (e), and precipitation (f) for the agricultural ecosystem of Northeast China to changes in SSCA.

In July and August, the responses of the agricultural climate showed more significant signals compared to that for May and June. Tmax in July-August is negatively correlated with SSCA $(\mathrm{R}=-0.470)$, which is significant at $p=0.005$. Tmin also exhibits a negative correlation with SSCA $(\mathrm{R}=-0.366, p=0.033)$. In contrast to the beginning growing season, SSCA and the precipitation over the agricultural ecosystem of NEC are found to be positively correlated, with a correlation coefficient of $0.365(p=0.034)$ for the primary precipitation season of NEC. 


\subsection{Sensitivity of the Agricultural Climate of Northeast China to Snow Cover Changes over Siberia}

We analyzed how variations in SSCA may influence anomalies in the temperature and precipitation for the growing season of the NEC agricultural ecosystem based on each cropland pixel (Figure 4). The linear regression analyses, using SSCA as the dependent variable and Tmax/Tmin/Precipitation as the independent variable, show that during the beginning of the growing season, both Tmin and precipitation respond negatively to positive SSCA anomalies by $-0.54 \pm 0.28^{\circ} \mathrm{C} / 10^{6} \mathrm{~km}^{2}(\mathrm{R}=-0.313$, $p=0.072)$ and $-0.18 \pm 0.16 \mathrm{~mm} / 10^{4} \mathrm{~km}^{2}(\mathrm{R}=-0.315, p=0.071)$, respectively. No significant correlation is obtained between SSCA variations and the corresponding Tmax variations during this period $(\mathrm{R}=0.071, p=0.703)$.

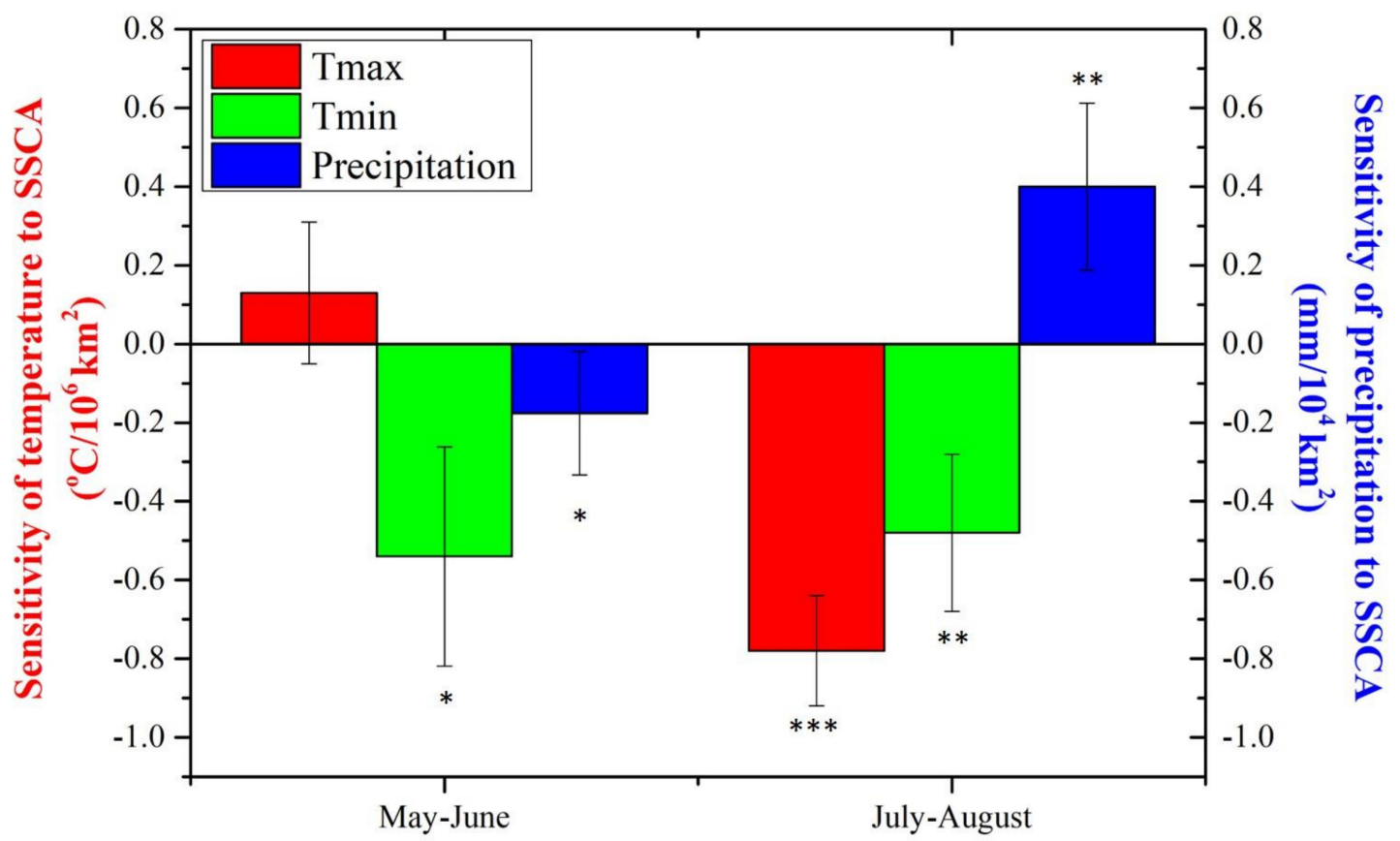

Figure 4. The sensitivity of Tmax, Tmin, and precipitation for the agricultural ecosystem of Northeast China to SSCA during the beginning growing season (May and June) and peak growing (July and August) season. The error bars are standard errors of the mean of the corresponding parameters. $* * *$ and ${ }^{* * *}$ indicate statistically significant at the $90 \%, 95 \%$, and $99 \%$ confidence level.

The climatic factors for the agricultural ecosystem in NEC respond more significantly (with $p<0.05$ ) in July-August than May-June to SSCA. Both Tmax and Tmin during the peak growing season are found to react negatively to positive anomalies of SSCA, with a sensitivity of $-0.78 \pm 0.14^{\circ} \mathrm{C} / 10^{6} \mathrm{~km}^{2}$ $(\mathrm{R}=-0.470, p=0.005)$ and $-0.49 \pm 0.2{ }^{\circ} \mathrm{C} / 10^{6} \mathrm{~km}^{2}(\mathrm{R}=-0.366, p=0.033)$, respectively. The sensitivity of precipitation for the peak growing season to the SSCA is $0.40 \pm 0.21 \mathrm{~mm} / 10^{4} \mathrm{~km}^{2}(\mathrm{R}=-0.365$, $p=0.034)$.

\subsection{Responses of Vegetation Growth of Northeast China to Snow Cover Changes over Siberia}

The responses of NDVI interannual changes during the beginning growing season and peak growing season of NEC to SSCA shows remarkable spatial heterogeneous patterns (Figure 5a,b). In most of the cold mountain regions (such as the Greater Khingan Range) and drier temperate areas (such as west part NEC), NDVI during the beginning growing season is negatively correlated with SSCA. Among the pixels with negative correlations, about $27.1 \%$ exhibit statistical significance at the 0.05 level. In contrast, in wetter temperate regions (such as the east part of NEC), interannual NDVI anomalies for the beginning of the growing season exhibit positive correlations with SSCA, with about $11.8 \%$ of these pixels showing statistical significance at the 0.05 level. 

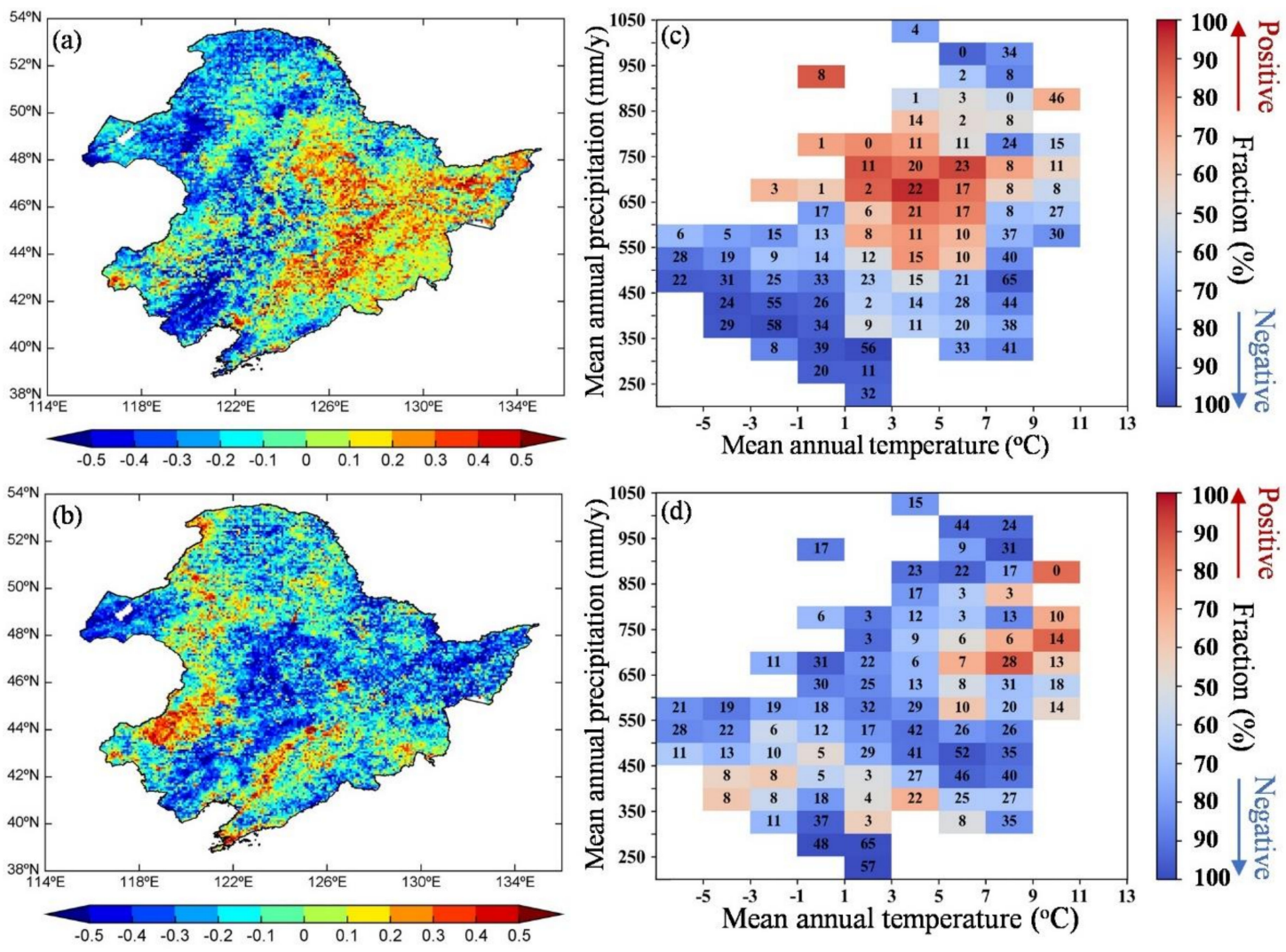

Figure 5. The response of the beginning growing season (May and June) and peak growing season (July and August) NDVI in Northeast China to changes in SSCA. (a) Spatial distribution of the correlation coefficient $\mathrm{R}$ between $\mathrm{NDVI}_{\mathrm{MJ}}$ in Northeast China and SSCA. (b) Spatial distribution of the correlation coefficient $\mathrm{R}$ between $\mathrm{NDVI}_{\mathrm{JA}}$ in Northeast China and SSCA. (c) Percentage of pixels with dominant (positive pixels $>50 \%$ or negative pixels $>50 \%$ ) correlation between $\mathrm{NDVI}_{\mathrm{MJ}}$ and SSCA (shown in a) in each $2{ }^{\circ} \mathrm{C}$ nterval of mean annual temperature and $50 \mathrm{~mm}$ interval of mean annual precipitation in the climate zone. (d) Same as c, but for the correlation between NDVI $_{J A}$ and SSCA (shown in b). The color bars in $\mathrm{c}$ and $\mathrm{d}$ represent the fraction of pixels with a dominant correlation between $\mathrm{NDVI}_{\mathrm{MJ}} / \mathrm{NDVI}_{\mathrm{JA}}$ and SSCA, and the numbers in each interval climate zone of $\mathrm{c}$ and $\mathrm{d}$ represent the percentage of pixels with significant correlation at $p<0.05$.

The temperature and precipitation interval analysis (Figure 5c) shows that the correlation between $\mathrm{NDVI}_{\mathrm{MJ}}$ of NEC and SSCA is negative over most dry temperate regions, with annual precipitation usually less than $500 \mathrm{~mm}$. In wetter temperate climate areas such as east of NEC Plain and Sanjiang Plain, where the annual precipitation is higher than $500 \mathrm{~mm}$, the $\mathrm{NDVI}_{\mathrm{MJ}}$ of $\mathrm{NEC}$ is positively correlated with SSCA. The significant positive correlated pixels are mainly concentrated at the $1-7^{\circ} \mathrm{C}$ temperature intervals. These opposite responses of $\mathrm{NDVI}_{\mathrm{MJ}}$ to SSCA between the wet and dry regions of the NEC can provide suggestions and projections for the management of the agricultural and grass ecosystem.

However, the correlation between $\mathrm{NDVI}_{\mathrm{JA}}$ and SSCA is found to be negative over most regions of NEC (Figure $5 b$ ). Over the areas with lower vegetation, such as grass or crops, $30.2 \%$ of the pixels are statistically significant at the 0.05 level. The influence of background climate on the correlation between $\mathrm{NDVI}_{\mathrm{JA}}$ and SSCA is not as evident as that during the beginning of the growing season (Figure $5 \mathrm{~d}$ ); $79.8 \%$ of the climate intervals show significant negative $\mathrm{NDVI}_{\mathrm{JA}}$ signals to increased SSCA in June and August, indicating more snow cover extent over Siberia may not be beneficial to vegetation growth in NEC during the peak growing season. 


\subsection{Sensitivity of Crop Growth of Northeast China to Snow Cover Changes over Siberia}

Last, we investigated how variations in SSCA may influence anomalies in $\mathrm{NDVI}_{\mathrm{MJ}}$ and $\mathrm{NDVI}_{\mathrm{JA}}$ for the agricultural ecosystem of NEC from 1982 to 2015, as calculated by linear regression. Over the whole agricultural ecosystem, the sensitivity of $\mathrm{NDVI}_{\mathrm{MJ}}$ and $\mathrm{NDVI}_{\mathrm{JA}}$ to SSCA are $0.30 \pm 2.26 \% / 10^{6} \mathrm{~km}^{2}$ $(\mathrm{R}=0.086, p=0.629)$ and $-1.61 \pm 2.13 \% / 10^{6} \mathrm{~km}^{2}(\mathrm{R}=0.392, p=0.022)$, respectively. This relatively large standard deviation can be explained by different responses of NDVI to SSCA variations at different climate backgrounds, as shown in Figure 4. Based on the temperature and precipitation intervals, we found that the sensitivity of $\mathrm{NDVI}_{\mathrm{MJ}}$ to SSCA is diverse across different climate conditions (Figure 6a). In the relatively dry regions where the annual precipitation is lower than $550 \mathrm{~mm}$, the sensitivity of $\mathrm{NDVI}_{\mathrm{MJ}}$ to SSCA ranges from -0.47 to $-4.91 \% / 10^{6} \mathrm{~km}^{2}$. In wetter areas where the precipitation higher than $550 \mathrm{~mm}$ and lower than $900 \mathrm{~mm}$, the sensitivity analysis indicates the increase of snow cover extent is beneficial to crop growth, especially for the areas where the annual mean temperature is lower than $7{ }^{\circ} \mathrm{C}$. The area with the highest sensitivity of $\mathrm{NDVI}_{\mathrm{MJ}}$ to SSCA is located at the $1-3^{\circ} \mathrm{C}$ annual temperature and 750-800 mm precipitation interval; with an increase of $10^{6} \mathrm{~km}^{2}$ snow cover area, the $\mathrm{NDVI}_{\mathrm{MJ}}$ can increase by $3.07 \%$.
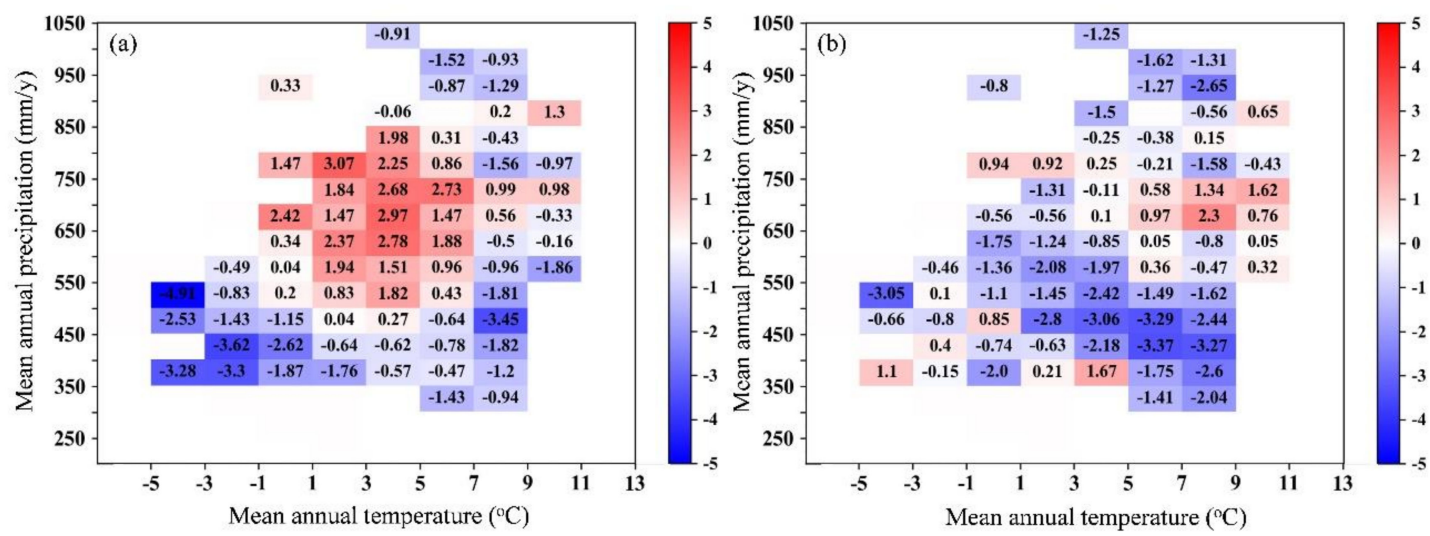

Figure 6. The sensitivity $\left(\% / 10^{6} \mathrm{~km}^{2}\right)$ of $\mathrm{NDVI}_{\mathrm{MJ}}(\mathbf{a})$ and $\mathrm{NDVI}_{\mathrm{JA}}(\mathbf{b})$ for the agricultural ecosystem of Northeast China to SSCA in each $2{ }^{\circ} \mathrm{C}$ interval of mean annual temperature and $50 \mathrm{~mm}$ interval of mean annual precipitation in the climate zones.

The sensitivity of $\mathrm{NDVI}_{\mathrm{JA}}$ to $\mathrm{SSCA}$ showed more consistent responses across different climate zones (Figure 6b). In general, with the increase of SSCA, the $\mathrm{NDVI}_{\mathrm{JA}}$ decreases in most climate zones. The $\mathrm{NDVI}_{\mathrm{JA}}$ of the agricultural ecosystem is extremely sensitive to SSCA in warmer and drier climate conditions, where the annual mean temperature ranges from 3 to $9{ }^{\circ} \mathrm{C}$, and the annual precipitation ranges from 400 to $500 \mathrm{~mm}$.

\section{Discussion}

\subsection{Impact of Snow Cover Changes over Siberia on Regional Climate and Vegetation Growth of Northeast China}

By using long-term satellite snow-cover records over Siberia and observational climate records over Northeast China, this study estimated the relationship between the SSCA variations and regional climate anomaly patterns of Northeast China from 1982 to 2015. Our results showed a significant correlation between temperature or precipitation of NEC and SSCA, which was consistent with some previous studies that focused on the relationship between snow cover in Eurasia and the regional climate of East Asia [14,15]. The difference between our study and these previous studies is that we focused on the status of local climate response during two critical vegetation growth periods: the beginning of the growing season and the peak growing season. We found different response patterns for both temperature and precipitation during different growing periods. Our results showed that both Tmin and precipitation during the beginning of the growing season of NEC are negatively 
correlated with SSCA, indicating the increase of SSCA corresponds to lower Tmin and less rainfall in May and June. While during the peak growing season of NEC, both Tmax and Tmin exhibit negative correlation with SSCA, precipitation shows opposite responses, indicating more SSCA corresponds to lower temperature (Tmax/Tmin) and more precipitation in NEC in July and August.

Our study also estimated the relationship between SSCA variations and NDVI of NEC, as well as the environmental factors influencing NDVI from 1982 to 2015 (Figures 5 and 7). During the beginning of the growing season, the correlation between SSCA and NDVI is found to be negative in the dry regions and positive in the wetter areas. Most of the dryland for agriculture in Northeast China is rainfed farmland [22]. Without irrigation, the sowing time and growth of crops for the relatively dry regions during the beginning of the growing season highly depend on the rainfall during this period [22]. The partial correlation between $\mathrm{NDVI}_{\mathrm{MJ}}$ and precipitation after controlling for Tmax, Tmin, and solar radiation (Figure 7a) confirmed the positive correlation between NDVI and precipitation for the dry regions, such as the west Jilin and Hulunbeir grasslands.
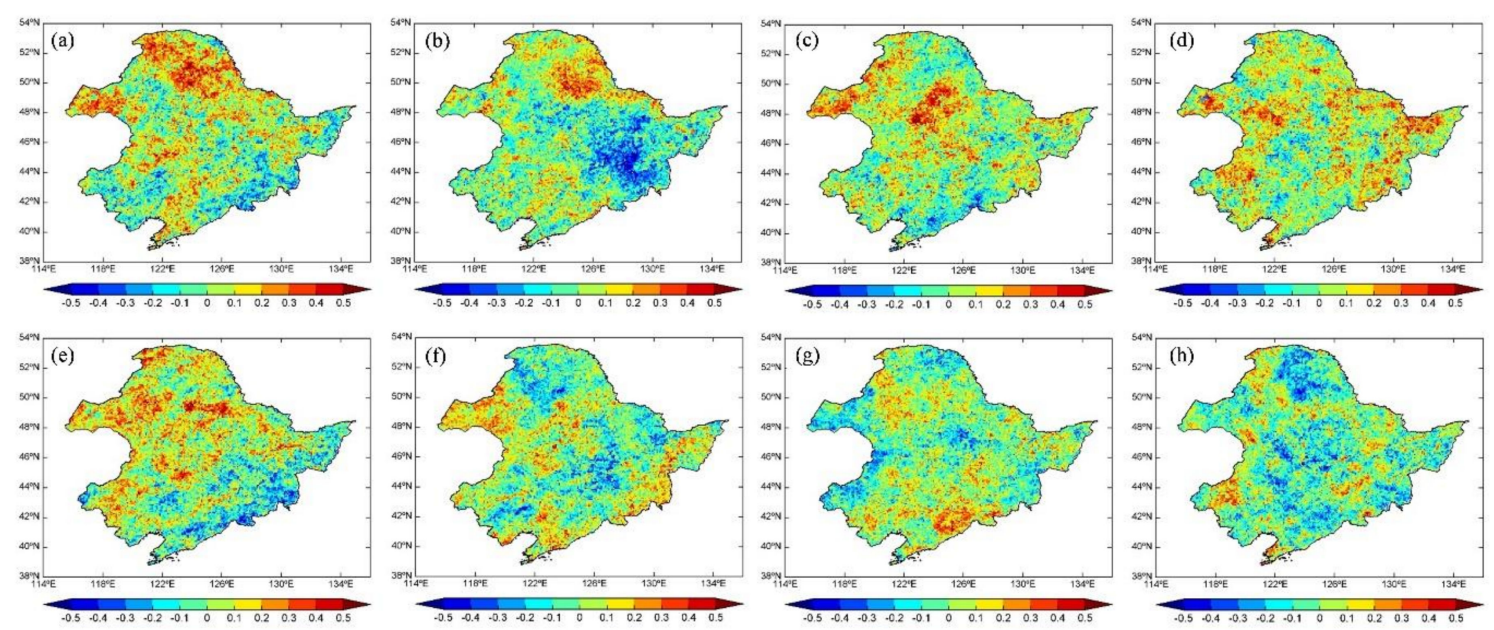

Figure 7. The response of NDVI to changes in Tmax, Tmin, precipitation, and solar radiation in Northeast China. (a) Spatial distribution of the partial correlation coefficient $\mathrm{R}$ between $\mathrm{NDVI}_{\mathrm{MJ}}$ and precipitation after controlling for Tmax, Tmin, and solar radiation. (b) Spatial distribution of the partial correlation coefficient $\mathrm{R}$ between $\mathrm{NDVI}_{\mathrm{MJ}}$ and Tmax after controlling for precipitation, Tmin, and solar radiation. (c) Spatial distribution of the partial correlation coefficient $\mathrm{R}$ between $\mathrm{NDVI}_{\mathrm{MJ}}$ and Tmin after controlling for precipitation, Tmax, and solar radiation. (d) Spatial distribution of the partial correlation coefficient $\mathrm{R}$ between $\mathrm{NDVI}_{\mathrm{MJ}}$ and solar radiation after controlling for Tmax, Tmin, and precipitation. Maps (e-h) are the same as (a-d) but for $\mathrm{NDVI}_{\mathrm{JA}}$.

Peng et al. (2013) suggested that the growing season NDVI is positively correlated with Tmin in Northeast China [28]. Previous studies also indicated that the NDVI responses to Tmin are opposite between the dry and wet climate conditions. For example, the increase of Tmin is calculated to decrease the rice yield in the Philippines where the climate is wet [31]; Wan et al. (2009) suggested the increase of Tmin can enhance vegetation growth in the temperate dry steppe in northern China [32]. In our case, the NDVI during different growing seasons shows different responses to Tmin (Figure 7c,g). In the beginning growing season, the NDVI is positively correlated to Tmin in temperature-limited high-latitude areas. In contrast, in the peak growing season, the NDVI and Tmin are found to be positively correlated in the low latitudes. These results suggested that the variations in SSCA correspond to different NDVI variations over NEC through regulating regional climate.

Furthermore, our study separated the growing season into a beginning growing season and peak growing season, and we found that the climate and NDVI response to the SSCA are quite different. The SSCA is calculated to correlate positively and significantly with both Tmax and Tmin, and negatively correlate with precipitation (statistically significant at the $95 \%$ confidence level) in the 
peak growing season for the agricultural ecosystem of NEC, which was consistent with Zhang and Li's study [15]. The expansion of the spring snow cover in Eurasia has been reported to favorably lower the $500 \mathrm{hPa}$ geopotential height over NEC in August, accompanied by the strengthening of the northwest airflow behind the trough, resulting in the low summer temperature in this region [15].

Crop growth in NEC, especially in the northern part, is highly limited by temperature, as indicated in Figure 7c,f [33]. The decrease in Tmax for the agricultural ecosystem of NEC in correspondence with the increased SSCA is not conducive to promote crop growth in the peak growing season. Simultaneously, the SSCA is positively correlated to rainfall in July and August, which may not be suitable for vegetation photosynthesis due to the insufficient solar radiation (Figure 7e,h).

\subsection{Sensitivity of Temperature/Precipitation and NDVI of Agricultural Ecosystems to Snow Cover Changes over Siberia}

The results of our temperature and precipitation sensitivity analysis confirm that SSCA played an essential role in affecting the regional climate in the agricultural ecosystem of NEC [14,15]. An increase of $10^{6} \mathrm{~km}^{2}$ in SSCA decrease Tmin and precipitation in May-June by $0.54{ }^{\circ} \mathrm{C}$ and $18 \mathrm{~mm}$, respectively. In the peak growing season, a rise of $10^{6} \mathrm{~km}^{2}$ in SSCA decrease both Tmax and Tmin by 0.78 and $0.49^{\circ} \mathrm{C}$, respectively, while this rise would increase precipitation by $40 \mathrm{~mm}$ for July-August.

The $\mathrm{NDVI}_{\mathrm{MJ}}$ and $\mathrm{NDVI}_{\mathrm{JA}}$ sensitivity analysis shows that an increase of $10^{6} \mathrm{~km}^{2}$ in SSCA increases $\mathrm{NDVI}_{\mathrm{MJ}}$ by $0.3 \%$ and decreases $\mathrm{NDVI}_{\mathrm{JA}}$ by $-0.61 \%$. These sensitivity results vary across different climate conditions, which is consistent with most previous studies. Our study also calculated the NDVI sensitivity to SSCA on each temperature and precipitation zone. Our results suggest that the precipitation background determines the $\mathrm{NDVI}_{\mathrm{MJ}}$ sensitivity, and temperature conditions dominate the $\mathrm{NDVI}_{\text {JA }}$ sensitivity for agricultural ecosystems to SSCA. It should be noted that this is only a sensitivity analysis; the driving mechanisms should be further investigated based on both in situ observation and dynamic vegetation model simulation.

\subsection{Uncertainties and Future Studies}

The monsoon precipitation dominates the summer precipitation in Northeast China [31]. Numerous studies have shown evidence that more snow cover in Eurasia leads to poor Indian summer monsoon and bring less rainfall in Asia [12,13,34]. Our results show the remote responses of precipitation to SSCA are opposite in May-June and July-August, with negative correlations in May-June and positive correlations in July and August. This conclusion means the inverse connection between SSCA and India monsoon may not exist in July and August, which was consistent with a recent study indicating the widely recognized inverse relationship of central Eurasian spring snow cover with the Indian summer monsoon rainfall has disappeared since 1990 [35]. In the future, more observations and model simulations should be used to verify this result.

Furthermore, to better guide agricultural management, such as irrigation, sowing-time design, and crop-species selection, a field investigation and questionnaire survey to the farmers should be conducted in our further study to assure that the SSCA can be a faithful predictor for the regional climate and crop growth.

\section{Conclusions}

In this study, we investigated the teleconnection between SSCA and regional climate, as well as vegetation growth over NEC, based on long-term time-series satellite- and observation-based data. Changes of SSCA are more significantly correlated with Tmin rather than Tmax during the beginning of the growing season over NEC. For the peak growing season, both Tmax and Tmin are significantly and negatively correlated with SSCA. SSCA is found to be negatively related to rainfall during the beginning of the growing season while positively correlated to rainfall during the peak growing season for the agricultural ecosystem of NEC. The remote responses of NDVI to SSCA vary across different climate zones and different growing periods. The NDVI variations over cold and dry cultivated regions 
exhibit negative correlations with SSCA in May-June, which is opposite for the wetter areas. A negative correlation between $\mathrm{NDVI}_{\mathrm{JA}}$ over the agricultural ecosystem and SSCA during the peak growing season is also detected, implying the variations in SSCA might be an essential driving factor in affecting crop growth by modifying the regional climate of NEC. In summary, our results described here have significant implications for understanding remote responses of local agriculture to snow cover changes of $\mathrm{NH}$ under climate change. In the future, more in situ observations and model simulations should be conducted to verify our results.

Author Contributions: Conceptualization, methodology, and writing, L.Y.; snow cover data processing and writing, C.G.; analysis and writing, F.Y.; project administration and funding acquisition, S.Z. All authors have read and agreed to the published version of the manuscript.

Funding: This research was funded by the National Science and Technology basic Resources Survey Project, grant number, 2017FY101301, National Natural Science Foundation of China, grant number, 41701493, and a Strategic Priority Research Program (A) of the Chinese Academy of Sciences, grant number, XDA2003020301.

Acknowledgments: The authors want to thank the anonymous reviewers for their valuable and constructive comments/suggestions to help improve the paper.

Conflicts of Interest: The authors declare no conflict of interest.

\section{References}

1. IPCC. A simple method for reconstructing a high-quality NDVI time-series data set based on the Savitzky-Golay filter. Remote Sens. Environ. 2013, 91, 332-344.

2. Chen, $\mathrm{X}$.; $\mathrm{Hu}, \mathrm{B}$; $\mathrm{Yu}, \mathrm{R}$. Spatial and temporal variation of phenological growing season and climate change impacts in temperate Eastern China. Glob. Chang. Biol. 2007, 11, 1118-1130. [CrossRef]

3. Groisman, P.Y.; Karl, T.R.; Knight, R.W. Observed impact of snow cover on the heat-balance and the rise of continental spring temperatures. Science 1994, 263, 198-200. [CrossRef] [PubMed]

4. Brown, R.D. Northern hemisphere snow cover variability and change, 1915-1997. J. Clim. 2000, 13, 2339-2355. [CrossRef]

5. Yu, L.X.; Liu, T.X.; Zhang, S.W. Temporal and spatial changes in snow cover and the corresponding radiative forcing analysis in Siberia from the 1970s to the 2010s. Adv. Meteorol. 2017. [CrossRef]

6. Dye, D.G.; Tucker, C.J. Seasonality and trends of snow-cover, vegetation index, and temperature in Northern Eurasia. Geophys. Res. Lett. 2003, 30, 7. [CrossRef]

7. Brown, R.D.; Robinson, D.A. Northern hemisphere spring snow cover variability and change over 1922-2010 including an assessment of uncertainty. Cryosphere 2011, 5, 219-229. [CrossRef]

8. Fernandes, R.; Zhao, H.X.; Wang, X.J.; Key, J.; Qu, X.; Hall, A. Controls on northern hemisphere snow albedo feedback quantified using satellite earth observations. Geophys. Res. Lett. 2009, 36, 21. [CrossRef]

9. Hall, A.; Qu, X. Using the current seasonal cycle to constrain snow albedo feedback in future climate change. Geophys. Res. Lett. 2006, 33, 3. [CrossRef]

10. Groisman, P.Y.; Karl, R.T.; Knight, R.W.; Stenchikov, G.L. Changes of snow cover, temperature, and radiative heat-balance over the northern-hemisphere. J. Clim. 1994, 7, 1633-1656. [CrossRef]

11. Euskirchen, E.S.; Mcguire, A.D.; Chapin, F.S. Energy feedbacks of northern high-latitude ecosystems to the climate system due to reduced snow cover during 20th century warming. Glob. Chang. Biol. 2007, 13, 2425-2438. [CrossRef]

12. Barnett, T.P.; Dümenil, L.; Schlese, U.; Roeckner, E. The effect of Eurasian snow cover on global climate. Science 1988, 239, 504-507. [CrossRef] [PubMed]

13. Bamzai Anjuli, S.; Shukla, J. Relation between Eurasian snow cover, snow depth, and the indian summer monsoon: An observational study. J. Clim. 1999, 12, 3117-3132. [CrossRef]

14. Wu, B.Y.; Yang, K.; Zhang, R.H. Eurasian snow cover variability and its association with summer rainfall in China. Adv. Atmos. Sci. 2009, 26, 31-44. [CrossRef]

15. Zhang, Q.; Li, D.L. Influence of winter and spring snow cover in Eurasia and Northeast China on summer air temperature over Northeast China. J. Glaciol. Geocryol. 2012, 34, 284-295. 
16. Grippa, M.; Kergoat, L.; Le Toan, T.; Mognard, N.M.; Delbart, N.; L'Hermitte, J.; Vicente-Serrano, S.M. The impact of snow depth and snowmelt on the vegetation variability over Central Siberia. Geophy. Res. Lett. 2005, 32, 21. [CrossRef]

17. Peng, S.S.; Piao, S.L.; Ciais, P.; Fang, J.Y.; Wang, X.H. Change in winter snow depth and its impacts on vegetation in China. Glob. Chang. Biol. 2010, 16, 3004-3013. [CrossRef]

18. Wang, T.; Peng, S.S.; Lin, X.; Chang, J.F. Declining snow cover may affect spring phenological trend on the Tibetan Plateau. Proc. Natl. Acad. Sci. USA 2013, 110, E2854-E2855. [CrossRef]

19. Yu, L.X.; Liu, T.X.; Bu, K.; Yan, F.Q.; Yang, J.C.; Chang, L.P.; Zhang, S.W. Monitoring the long term vegetation phenology change in Northeast China from 1982 to 2015. Sci. Rep. 2017, 7, 1-9. [CrossRef]

20. Yu, L.X.; Liu, T.X.; Cai, H.Y.; Tang, J.M.; Bu, K.; Yan, F.Q.; Yang, C.B.; Yang, J.C.; Zhang, S.W. Estimating land surface radiation balance using modis in Northeastern China. J. Appl. Remote Sens. 2014, 8, 083523. [CrossRef]

21. Yu, L.X.; Zhang, S.W.; Tang, J.M.; Liu, T.X.; Bu, K.; Yan, F.Q.; Yang, C.B.; Yang, J.C. The Effect of deforestation on the regional temperature in Northeastern China. Theor. Appl. Climatol. 2015, 120, 761-771. [CrossRef]

22. Yu, L.X.; Liu, T.X. The Effect of Land Use/Cover Changes on Regional Climate in Northeast China; Beijing Science Press: Beijing, China, 2019.

23. Fu, C.B. Influence of winter and spring snow cover in Eurasia and Northeast China on summer air temperature over Northeast China. Acta Meteorol. Sin. 1980, 38, 187-192.

24. Robinson, D.A.; Estilow, T.W.; NOAA CDR Program. Noaa Climate Data Record (Cdr) of Northern Hemisphere (Nh) Snow Cover Extent (Sce), Version 1; National Climatic Data Center (NCDC): Asheville, NC, USA, 2012.

25. Helfrich, S.R.; McNamara, D.; Ramsay, B.H.; Baldwin, T.; Kasheta, T. Enhancements to, and forthcoming developments in the interactive multisensor snow and ice mapping system (Ims). Hydrol. Process. 2007, 21, 1576-1586. [CrossRef]

26. Tucker, C.J.; Pinzon, J.E.; Brown, M.E.; Slayback, D.A.; Pak, E.W.; Mahoney, R.; Vermote, E.F.; Saleous, N. An extended Avhrr 8-Km Ndvi dataset compatible with modis and spot vegetation Ndvi data. Int. J. Remote Sens. 2005, 26, 4485-4498. [CrossRef]

27. Piao, S.L.; Fang, J.Y.; Zhou, L.M.; Ciais, P.; Zhu, B. Variations in satellite-derived phenology in China's temperate vegetation. Glob. Chang. Biol. 2006, 12, 672-685. [CrossRef]

28. Peng, S.S.; Piao, S.L.; Ciais, P.; Myneni, R.B.; Chen, A.P.; Chevallier, F.; Dolman, A.J.; Janssens, I.A.; Penuelas, J.; Zhang, G.X.; et al. Asymmetric effects of daytime and night-time warming on northern hemisphere vegetation. Nature 2013, 501, 88. [CrossRef]

29. Yu, L.X.; Xue, Y.K.; Diallo, I. Vegetation greening in China and its effect on summer regional climate. Sci. Bull. 2020. [CrossRef]

30. Pearson, K. Notes on regression and inheritance in the case of two parents. Proc. R. Soc. Lond. 1895, 58, $240-242$.

31. Peng, S.; Huang, J.; Sheehy, J.E.; Laza, R.C.; Visperas, R.M.; Zhong, X.; Centeno, G.S.; Khush, G.S.; Cassman, K.G. Rice yields decline with higher night temperature from global warming. Proc. Natl. Acad. Sci. USA 2004, 101, 9971-9975. [CrossRef]

32. Wan, S.Q.; Xia, J.Y.; Liu, W.X.; Niu, S.L. Photosynthetic overcompensation under nocturnal warming enhances grassland carbon sequestration. Ecology 2009, 90, 2700-2710. [CrossRef]

33. Piao, S.L.; Ciais, P.; Huang, Y.; Shen, Z.H.; Peng, S.S.; Li, J.S.; Zhou, L.P.; Liu, H.Y.; Ma, Y.C.; Ding, Y.H.; et al. The impacts of climate change on water resources and agriculture in China. Nature 2010, 467, 43-51. [CrossRef] [PubMed]

34. Barnett, T.P.; Dumenil, L.; Schlese, U.; Roeckner, E.; Latif, M. The effect of Eurasian snow Cover on regional and global climate variations. J. Atmos. Sci. 1989, 46, 661-685. [CrossRef]

35. Zhang, T.T.; Wang, T.; Krinner, G.; Wang, X.Y.; Gasser, T.; Peng, S.S.; Piao, S.L.; Yao, T.D. The weakening relationship between eurasian spring snow cover and indian summer monsoon rainfall. Sci. Adv. 2019, 5, eaau8932. [CrossRef] [PubMed]

(C) 2020 by the authors. Licensee MDPI, Basel, Switzerland. This article is an open access article distributed under the terms and conditions of the Creative Commons Attribution (CC BY) license (http://creativecommons.org/licenses/by/4.0/). 